\title{
DNA fingerprinting of Paecilomyces strains of potential use for the biological control of pests
}

\author{
Peter W. Inglis*, Rubia B.C. Sarmento, Camila F.C. Gavião and M. Cléria Valadares-Inglis \\ Biological Control (PCB), EMBRAPA Recursos Genéticos e Biotecnologia, C.P. 02372, CEP 70770-900, Brasília, \\ D.F, Brazil \\ *Author for correspondence: Tel.: +55-61-348-4675, Fax: +55-61-348-4673, E-mail: peteringlis@onetel.com
}

Received 14 April 2005; accepted 10 May 2005

Keywords: Biological control, entomopathogenic fungi, intron splice site PCR, polymorphism, RFLP, telomere fingerprint

\begin{abstract}
Summary
Telomeric fingerprinting was found to be highly differentiating for Paecilomyces fumosoroseus and Paecilomyces lilacinus isolates in comparison to intron splice site PCR and is therefore a good method for quality control of future products based on these fungi. Although the telomeric restriction length polymorphisms correctly divided the isolates into their appropriate species, further correlation with host range or geographical origin of the isolates was not found. In this respect, intron splice site PCR was more informative taxonomically. The chromosome numbers inferred from telomeric fingerprints were seven chromosomes for P. lilacinus and between six and nine chromosomes for P. fumosoroseus.
\end{abstract}

\section{Introduction}

Paecilomyces fumosoroseus and Paecilomyces lilacinus (Deuteromycotina: Hyphomycetes) are fungi currently receiving attention for their potential in biological control programmes. $P$. fumosoroseus isolates are commonly entomogenous, are found infecting many different orders of insects in all stages of the life-cycle, are geographically widespread and can also be isolated from soil samples (Samson 1974). This fungus is being developed for use against a range of agricultural pests, including the whitefly, Bemisia tabaci (Osborne \& Landa 1992; Lacey et al. 1993), where biocontrol may offer an effective alternative for control of insects becoming highly resistant to conventional pesticides. P. lilacinus is frequently isolated from soil, particularly in samples originating from warmer regions (Domsch et al. 1980). Some strains have been shown to be mycoparasitic, colonizing fungal sclerotia (Gupta et al. 1993). There have also been reports of invasive mycoses caused by opportunistic $P$. lilacinus in immunocompromised patients (Orth et al. 1996). Of particular interest, however, are the entomogenous (Rombach et al. 1986) and nematogenous (Carneiro 1992; Holland et al. 1999; Gunasekera et al. 2000) strains of $P$. lilacinus.

An analysis of the efficacy of biopesticides requires the accurate monitoring of the released strain in the field and the reliable differentiation of that strain from those possibly endemic to the application site or target. The initial identification and differentiation of fungal strains is often difficult, where a combination of morphological, biochemical and virulence tests, and access to typestrains are required for reliable identification (Samson 1974). Molecular markers are attractive alternatives for fungal identification and fingerprinting, where the often simple and standard techniques are now generally available. Arbitrarily primed PCR (Williams et al. 1990) was previously used to analyse strains of $P$. $f u$ mosoroseus (Tigano-Milani et al. 1995a; Cantone \& Vandenberg 1998) and P. lilacinus (Tigano-Milani et al. 1995b; Gunasekera et al. 2000). Another technique, which has successfully differentiated commercial yeast strains, is PCR using consensus intron splice site primers (de Barros Lopes et al. 1996). Such analyses can reveal genetic diversity among strains and furthermore can demonstrate the extent of geographical or host distribution of related strains.

Although simple and economical for the screening of large numbers of isolates, PCR-based methods may not be sensitive or reproducible enough to differentiate closely related strains, particularly where quality control or verification of released strains is required. In this respect, detection of restriction fragment length polymorphisms (RFLPs) using multi-copy genes as probes is an alternative technique that has been applied in several fungi as a distinguishing marker. Telomeric DNA probes were successfully used to fingerprint strains of Beauveria bassiana (Viaud et al. 1996), Botrytis cinerea (Levis et al. 1997) and Metarhizium anisopliae var. acridum (Inglis et al. 1999). We therefore evaluated the 
potential of telomeric fingerprinting to differentiate some $P$. fumosoroseus and $P$. lilacinus strains in comparison with a PCR-based technique using fungal intron splice site primers (de Barros Lopes et al. 1996).

\section{Materials and methods}

\section{Fungal strains}

P. fumosoroseus and P. lilacinus isolates (Table 1) were obtained as liquid nitrogen-stored cultures from the EMBRAPA Recursos Genéticos e Biotecnologia collection of entomopathogenic fungi. The strains selected for analysis conformed to the typical descriptions of $P$. fumosoroseus and P. lilacinus, using classical morphological characteristics (Samson 1974). Cultures for preparation of conidia were plated on potato dextrose agar (Difco) and incubated at $28{ }^{\circ} \mathrm{C}$ for $7-10$ days.

\section{DNA fingerprinting methods}

Isolates for extraction of genomic DNA for restriction enzyme digests and PCR, were grown for $48 \mathrm{~h}$ in $200 \mathrm{ml}$ Aspergillus complete medium (Pontecorvo et al. 1953) in $500 \mathrm{ml}$ Erlenmeyer flasks at $28{ }^{\circ} \mathrm{C}$ with shaking at $200 \mathrm{rev} / \mathrm{min}$. Mycelium was then harvested by filtration, washed with sterile distilled water and ground to a powder in liquid nitrogen. Genomic DNA was then extracted using a CTAB extraction method (Rogers \& Bendich 1988), modified by the addition of a phenol extraction step to remove residual nuclease activity. Genomic DNA $(1 \mu \mathrm{g})$ from each isolate was digested with $E c o$ RI for $3 \mathrm{~h}$ in the appropriate buffer. Following electrophoresis, DNA fragments were alkaline $(0.4 \mathrm{M}$ $\mathrm{NaOH}$ ) blotted on to a positively charged nylon hybridization membrane (Hybond XL, Amersham).

Table 1. Origin and classification of Paecilomyces isolates.

\begin{tabular}{llll}
\hline Isolate $^{\mathrm{a}}$ & Host or substrate & Location & Year \\
\hline P. fumosoroseus & & & \\
CG35 & Soil & Brasília-DF, Brazil & 1991 \\
CG202 & Musca domestica & France & 1985 \\
CG203 & Bemisia tabaci & Florida, USA & 1990 \\
CG205 & Bemisia tabaci & Florida, USA & 1992 \\
CG404 & Bemisia tabaci & Kathmandu/Nepal & 1992 \\
CG436 & Bemisia tabaci & India & 1992 \\
CG456 & Pieris brassicae & France & 1978 \\
CG686 & Bemisia sp. & Mexico & 1990 \\
CG688 & Bemisia tabaci & Texas, USA & 1992 \\
CG736 & Bombyx mori & Japan & 1998 \\
CG738 & Plutella xylostella & Philippines & 1989 \\
P. lilacinus & & & \\
CG189 & Soil & GO, Brazil & 1991 \\
CG262 & Soil & TO, Brazil & 1991 \\
CG362 & Soil & GO, Brazil & 1991 \\
CG638 (=CBS284.36) & Soil & USA & 1936 \\
\hline
\end{tabular}

${ }^{\mathrm{a}} \mathrm{CG}=\mathrm{CENARGEN/EMBRAPA}$ Entomopathogenic Fungus Collection, Brasília, Brazil.
Similar blots were prepared with DNA digested with the restriction enzymes BamHI and HindIII. Telomeric DNA was synthesized by PCR using a pair of selfcomplimentary telomeric primers ([TTAGGG] $]_{4}$, and [CCCTAA $]_{4}$ ) (Ijdo et al. 1991) and was labelled with $\left[\alpha-{ }^{32} \mathrm{P}\right] \mathrm{dCTP}$ using a random primer labelling kit (Rediprime II, Amersham). Hybridizations, high stringency washes and signal detection were carried out using standard techniques.

PCR-based fingerprinting using fungal intron splice site primers: EI1, CTGGCTTGGTGTATGT; EI2, CTGGCTTGCTACATAC; LA1, GCGACGGTGTACTAAC; LA2, CGTGCAGGTGTTAGTA, was carried out essentially as described previously (de Barros Lopes et al. 1996), using $20 \mathrm{ng}$ fungal DNA, prepared as above, per reaction. PCR products were resolved by electrophoresis on $1.5 \% \mathrm{w} / \mathrm{v}$ agarose gels and bands detected by ethidium bromide staining.

\section{Data analysis}

Bands hybridizing with the telomeric probe were scored $(1=$ present; $0=$ absent $)$ as binary characters and data combined from the three different restriction enzymes utilized. Data was then analysed using the NT-SYS-pc V1.8 package (Rohlf 1993). Similarity matrices were calculated using the Jaccard coefficient (Sneath \& Sokal 1973), which considers only the joint presence of a character as an indication of similarity. Clustering of the similarity data was done using the unweighted pairgroup method, arithmetic mean (UPGMA; Sneath \& Sokal 1973) and a summary dendrogram of similarity data produced. Amplified PCR products from gel photographs were similarly scored.

\section{Results and discussion}

Telomeric fingerprinting was found to be highly differentiating for the strains of $P$. fumosoroseus and $P$. lilacinus tested in this study, producing unique profiles for all strains with each of the three restriction enzymes used (Figure 1). The three different restriction enzymes yielded a total of 167 binary characters derived from unambiguously readable bands. An UPGMA dendrogram summarizing the results of cluster analysis of the data (Figure 2) showed that P. fumosoroseus and $P$. lilacinus isolates formed distinct clades with very low similarity to each other. However, the similarity between individuals in these clades was also extremely low, approaching that of the inter-species branch. No host or geographical relationships could be discerned in the dendrogram, where $P$. fumosoroseus strains isolated from soil, the whitefly, Bemisia tabaci or from other insects failed to form coherent groups. The apparent hypervariability of the subtelomeric DNA in these strains could indicate high genetic instability in these loci. For this reason, temporal studies are required to determine short and medium-term stability of the fin- 

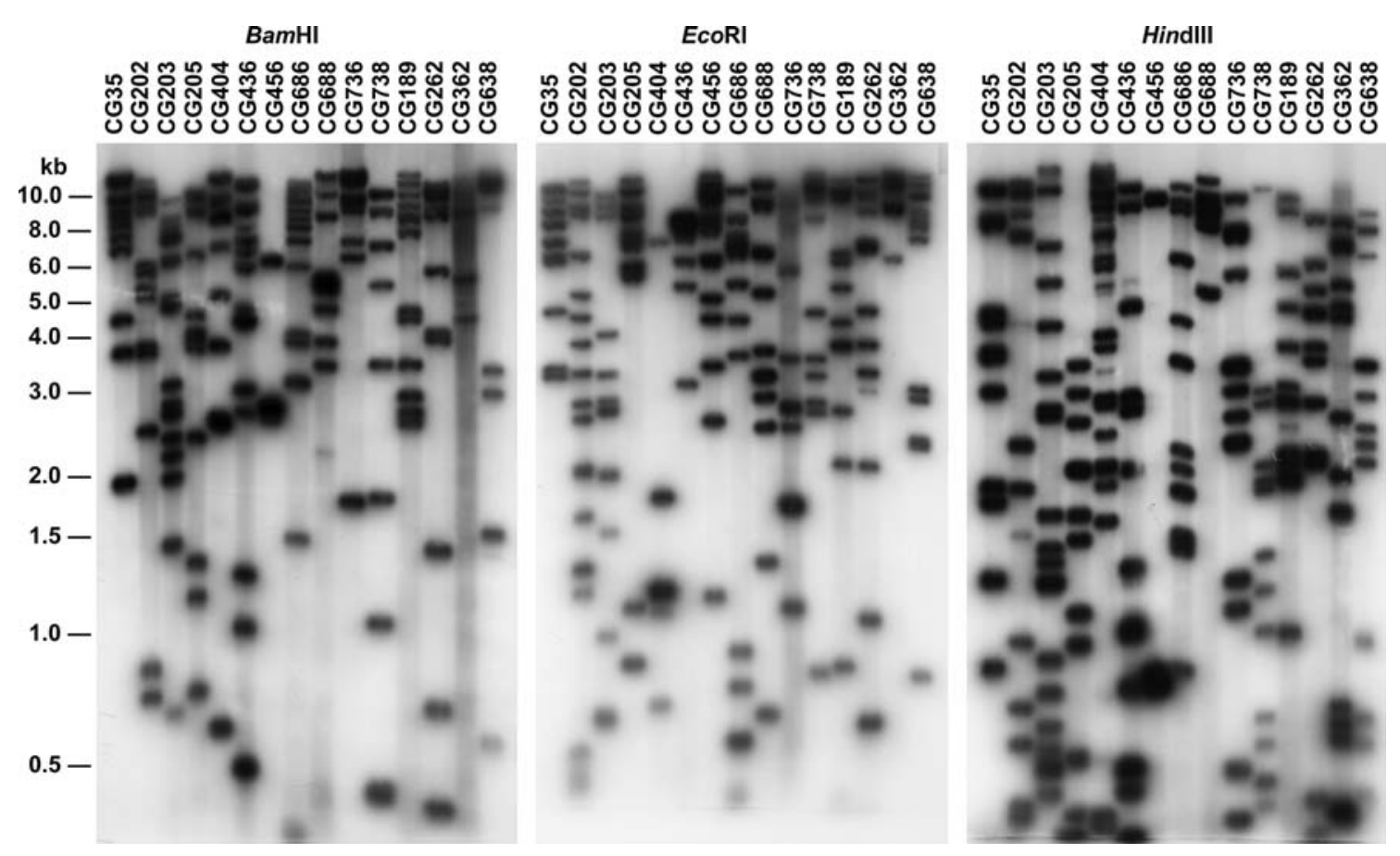

Figure 1. Telomeric fingerprint autoradiograms of P. fumosoroseus and P. lilacinus isolates. Molecular weight scale was estimated using the $1 \mathrm{~kb}$ DNA ladder (Amersham).

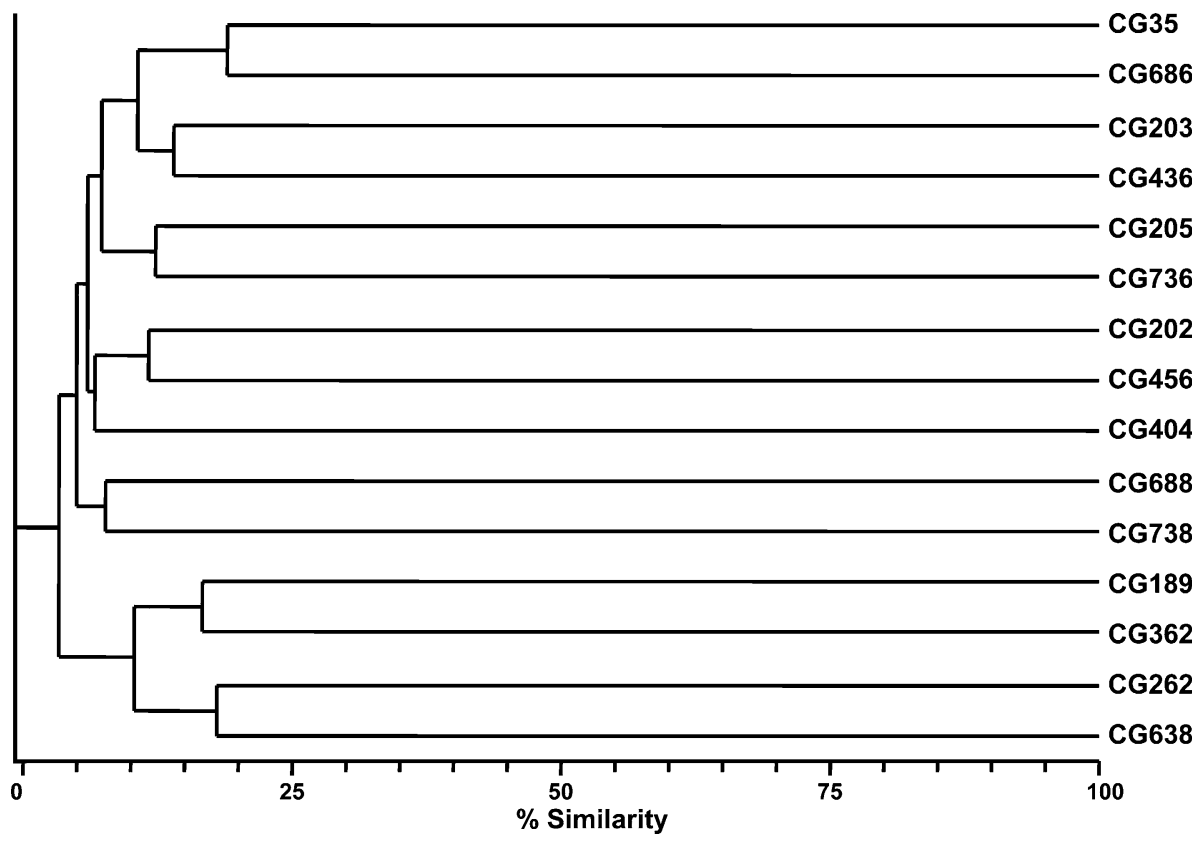

Figure 2. Dendrogram of combined telomeric fingerprinting data. A similarity matrix was calclulated, based on the Jaccard coefficient, and the tree drawn using the unweighted pair group arithmetic mean method (UPGMA).

gerprints obtained. In this respect, it was interesting to note that among the four $P$. lilacinus strains analysed, the telomeric fingerprint of one strain isolated in 1936 in the USA (CG638) was closer to one of three Brazilian strains isolated in 1991 (CG262) than were the three Brazilian strains to each other.

In all four $P$. lilacinus isolates examined, a chromosome number of seven may be inferred by the number of bands resolved in the telomeric fingerprints (Table 2). In contrast, the inferred chromosome number among the $P$. fumosoroseus isolates varied between six and nine chromosomes. These chromosome number estimates and variation within species are consistent with previously published data on entomopathogenic Deuteromycetes. Here, pulsed field electrophoretic karyotyping showed that the DNA of a single strain of $P$. fumosoroseus could be resolved into six chromosome-sized bands (Shimizu et al. 1991) and in Metarhizium anisopliae, an 
Table 2. Number of chromosomes in Paecilomyces isolates inferred by the number of bands which hybridized with the telomeric probe.

\begin{tabular}{lllll}
\hline Isolate & \multicolumn{2}{l}{$\begin{array}{l}\text { Number of bands per restric- } \\
\text { tion enzyme }\end{array}$} & \\
\cline { 2 - 4 } & BamHI & Eco RI & HindIII & \\
\hline CG35 & 11 & 14 & 13 & 7 \\
CG202 & 14 & 17 & 14 & 9 \\
CG203 & 18 & 12 & 18 & 9 \\
CG205 & 13 & 12 & 11 & 7 \\
CG404 & 12 & 6 & 18 & 9 \\
CG436 & 17 & 9 & 13 & 9 \\
CG456 & 4 & 15 & 2 & 8 \\
CG686 & 15 & 16 & 12 & 8 \\
CG688 & 11 & 12 & 6 & 6 \\
CG736 & 9 & 13 & 13 & 7 \\
CG738 & 9 & 13 & 13 & 7 \\
CG189 & 14 & 14 & 14 & 7 \\
CG262 & 11 & 14 & 12 & 7 \\
CG362 & 10 & 6 & 14 & 7 \\
CG638 & 10 & 14 & 14 & 7 \\
\hline
\end{tabular}

electrophoretic karyotype of between seven and eight chromosomes was reported for several strains (Valadares-Inglis \& Peberdy 1998). Electrophoretic karyotype estimates appear to be generally consistent with chromosome numbers inferred from telomeric fingerprints in these fungi, where in Metarhizium flavoviride between five and seven chromosomes were inferred among a collection of eight isolates (Inglis et al. 1999). Gain or loss of dispensable chromosomes by anastomosis and non-reciprocal crosses with other compatible strains in the field could be an explanation for variations in telomere banding pattern and inferred chromosome number, apart from that resulting from possible limitations of electrophoretic resolution (both standard agarose gel electrophoresis of restriction fragments and pulsed field electrophoresis). At least 20 vegetative compatibility groups have been detected in P. fumosoroseus isolates, indicating that chromosome exchange among field strains is possible (Cantone \& Vandenberg 1998). Interestingly, digestion with certain restriction enzymes produced an anomalously low number of bands in fingerprints in certain strains, such as CG456, where a particular band could appear with greater intensity than usual. This effect could be the result of duplication of a telomere-associated sequence to different telomeres.

Intron splice site PCR of the Paecilomyces isolates was found to be less differentiating than telomeric fingerprinting and required the combination of the results from the four different primers to distinguish all strains. PCR with primers EI1, EI2 or LA1 gave rise to multiple products with a wide molecular weight range (Figure 3). In contrast, primer LA2 resulted in poor amplification of Paecilomyces DNA and reproducibly failed to produce a PCR product with $P$. fumosoroseus strain CG738 DNA. A large variation in PCR band intensity was found, where some products were clearly preferentially amplified in some strains and bands of the same apparent molecular weight varied in intensity

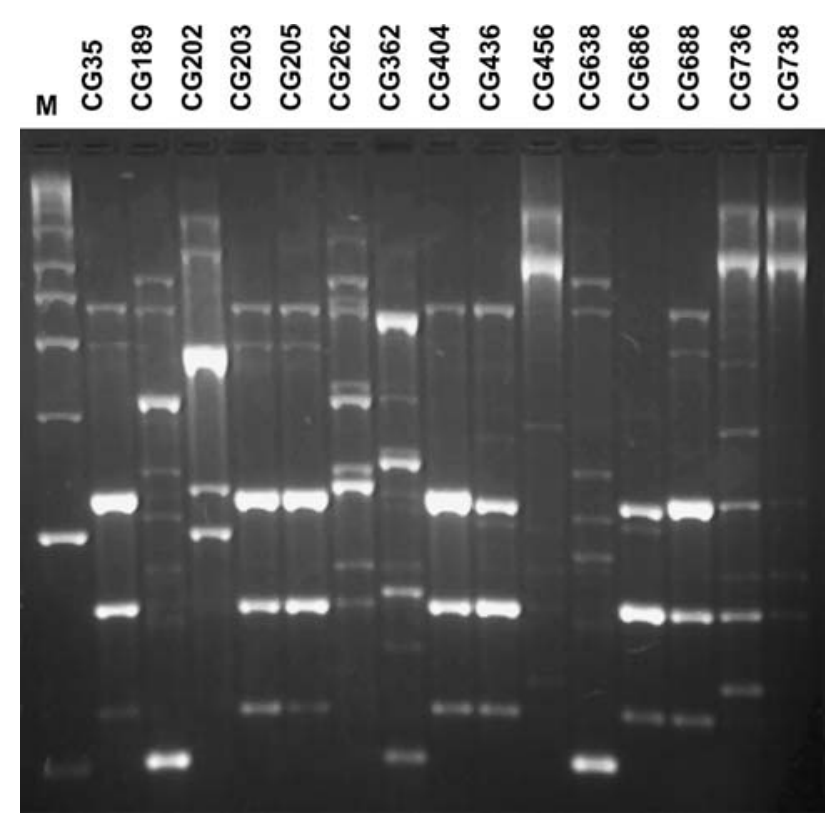

Figure 3. Example of intron splice site PCR, using primer EI2, of $P$. fumosoroseus and P. lilacinus isolates. Molecular weight marker (M) was the $1 \mathrm{~kb}$ DNA ladder (Amersham).

between certain samples. Additionally, a significant proportion of the higher molecular weight bands could not be reliably scored under the electrophoretic conditions used. The variability in band intensities obtained is a potential disadvantage of the technique, which is probably related to exhaustion of PCR reagents in individual reactions. This could clearly lead to variation in profiles obtained, which are already dependent on multiple technical factors, including different sources and quality of PCR reagents, use of different PCR machines with varying thermal properties and variation in the quality of template DNA, which is difficult to standardize. Nevertheless, the four different intron splice site primers yielded a total of 65 binary characters.

Cluster analysis of the PCR data (Figure 4) showed that, as in the case of telomeric RFLPs, the strains analysed grouped in their respective species. In this case, however, all the $P$. fumosoroseus strains isolated from Bemisia spp. formed a distinct, apparently monophyletic group. This group then formed a clade with the $P$. $f u$ mosoroseus strains CG736 and CG738, which although isolated from different hosts, namely Bombxy mori and Plutella xylostella, both originated in Asia. The remaining $P$. fumosoroseus, both originating in France, then completed the $P$. fumosoroseus group. This data is consistent with a proposed co-evolution of host specialized P. fumosoroseus genotypes on Bemisia whiteflies originating in India (Brown 1994), which have then recently spread along with their host to Europe, Africa and the Americas (Horowitz 1986). The molecular evidence for this theory has been provided elsewhere by restriction analysis of amplified rDNA-ITS, where clustering of P. fumosoroseus isolates from Bemisia was 


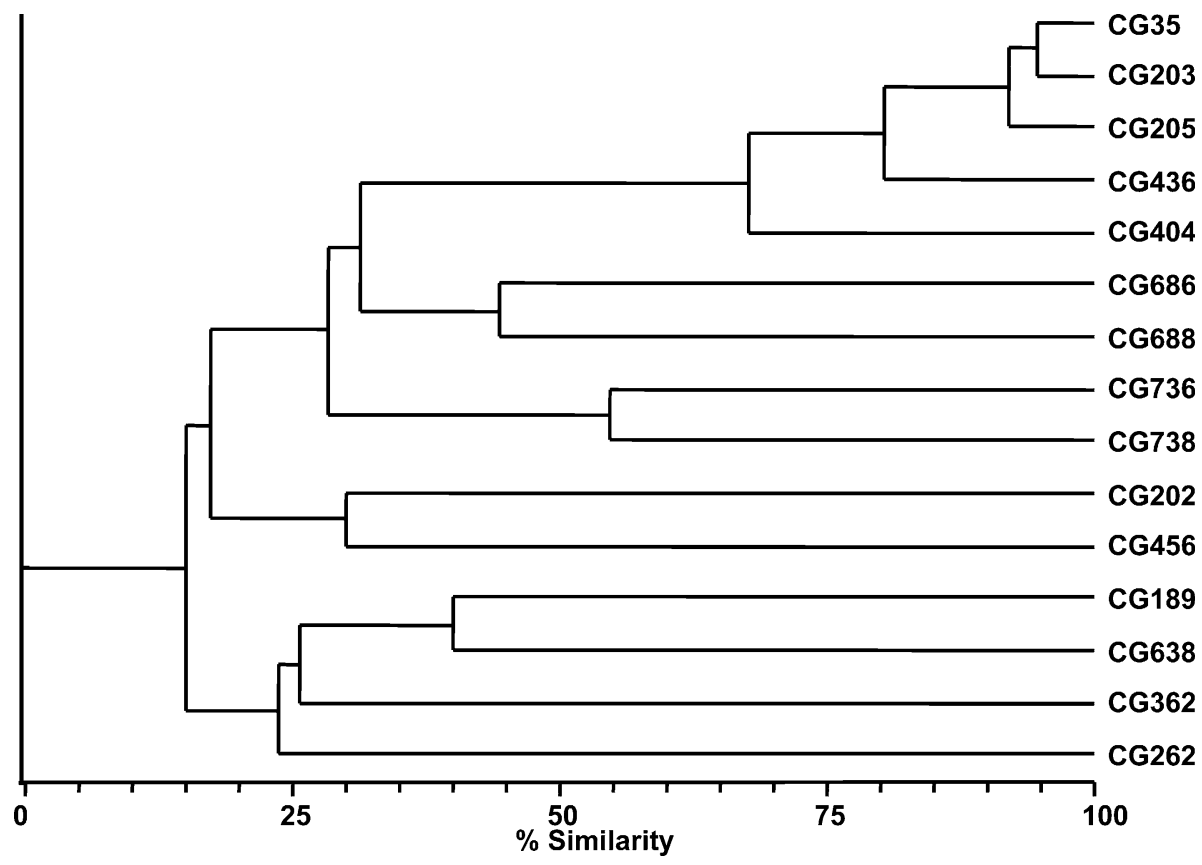

Figure 4. UPGMA dendrogram of combined intron splice site PCR data.

evident, regardless of geographical origin (Fargues et al. 2002).

\section{Conclusions}

Our results indicate that telomere fingerprinting is highly suitable for strain definition and quality control of potential biocontrol agents based on Paecilomyces strains. However, the technique is probably not suitable for large-scale monitoring of numerous environmental isolates, where cost and time are important considerations. Here, our results show that intron splice site PCR could be suitable for this type of monitoring, where even a single primer could be sufficient for screening large numbers of isolates recovered from field release trials. The taxonomic information provided by the two tested techniques differed notably, where our data indicated that telomeric fingerprinting is probably not suitable or reliable for defining taxonomic relationships above the strain level in P. fumosoroseus and $P$. lilacinus. Nor is the technique suitable for an assessment of the overall taxonomic similarity between two related individuals. In this case, our results suggest that multi-locus PCR-based techniques using primers binding throughout the genome can provide more significant information in these fungi.

\section{Acknowledgements}

PWI was the recipient of a Postdoctoral fellowship from $\mathrm{CNPq}$ during this research. The authors also wish to thank EMBRAPA for studentships for RBCS and CFCG and for a program grant to MCV-I.

\section{References}

Barros Lopes, M., Soden, A., Henschke, P.A. \& Langridge, P. 1996 PCR differentiation of commercial yeast strains using intron splice site primers. Applied and Environmental Microbiology 62, 45144520.

Brown, J.K. 1994 Current status of Bemisia tabaci as a plant pest and virus vector in agrosystems worldwide. FAO Plant Protection Bulletin 42, 3-32.

Cantone, F.A. \& Vandenberg, D. 1998 Intraspecific diversity in Paecilomyces fumosoroseus. Mycological Research 102, 209-215.

Carneiro, R.M.D.G. 1992 Princípios e tendências de controle biologíco de nematóides com fungos nematófagos. Pesquisa Agropecuária Brasileira 27, 113-121.

Domsch, K.H., Gams, W. \& Anderson, T.H., (1980). Compendium of Soil Fungi, Vol. 1, London: Academic Press. ISBN 0-12-220401-8.

Fargues, J., Bon, M.C., Manguin, S. \& Couteaudier, Y. 2002 Genetic variability among Paecilomyces fumosoroseus isolates from various geographical and host insect origins based on the rDNA-ITS regions. Mycological Research 106, 1066-1074.

Gunasekera, T.S., Holland, R.J., Gillings, M.R., Briscoe, D.A., Neethling, D.C., Williams, K.L. \& Nevalainen, K.M.H. 2000 Phenotypic and genetic characterization of Paecilomyces lilacinus strains with biocontrol activity against root-knot nematodes. Canadian Journal of Microbiology 46, 775-783.

Gupta, S.C., Leathers, T.D. \& Wicklow, D.T. 1993 Hydrolytic enzymes secreted by Paecilomyces lilacinus cultured on sclerotia of Aspergillus flavus. Applied Microbiology and Biotechnology 39, 99103.

Holland, R.J., Williams, K.L. \& Khan, A. 1999 Infection of Meloidogyne javanica by Paecilomyces lilacinus. Nematology 1, 131-139.

Horowitz, A. 1986 Population dynamics of Bemisia tabaci (Gennadius) with special emphasis on cotton fields. Agriculture, Ecosystems and Environment 17, 37-47.

Ijdo, J.W., Wells, R.A., Baldini, A. \& Reeders, S.T. 1991 Improved telomere detection using a telomere repeat probe (TTAGGG)n generated by PCR. Nucleic Acids Research 19, 4780.

Inglis, P.W., Magalães, B.P. \& Valadares-Inglis, M.C. 1999 Characterisation of the entomopathogenic fungus, Metarhizium flavoviride using telomeric fingerprinting. FEMS Microbiology Letters 179, $49-52$. 
Lacey, L.A., Kirk, A.A., Millar, L., Mercadier, G. \& Vidal, C. 1993 Ovicidal and larvicidal activity of conidia and blastospores of Paecilomyces fumosoroseus (Deuteromycotina: Hyphomycetes) against Bemisia argentifolii (Homoptera: Aleyrodidae) with a description of a bioassay system allowing prolonged survival of control insects. Biocontrol Science and Technology 9, 9-18.

Levis, C., Giraud, T., Dutertre, M., Fortini, D. \& Brygoo, Y. 1997 Telomeric DNA of Botrytis cinerea: a useful tool for strain identification. FEMS Microbiology Letters 157, 267-272.

Orth, B., Frei, R., Itin, P.H., Rinaldi, M.G., Speck, B., Gratwohl, A. \& Widmer, A.F. 1996 Outbreak of invasive mycoses caused by Paecilomyces lilacinus from a contaminated skin lotion. Annals of Internal Medicine 125, 799-806.

Osborne, L.S. \& Landa, Z. 1992 Biological control of whiteflies with entomopathogenic fungi. Florida Entomologist 75, 456-471.

Pontecorvo, G., Roper, J.A., Hemons, L.M., MacDonald, K.D. \& Bufton, A.W.J. 1953 The genetics of Aspergillus nidulans. Advances in Genetics 5, 141-238.

Rogers, S.O. \& Bendich, A.J. 1988. Extraction of DNA from plant tissues. In: Plant Molecular Biology Manual Vol. A6, eds. Gelvin S.B., Schilperpoort R.A. \& Verma D.P.S. pp. 1-10. Dordrecht: Kluwer Acadademic Publishers. ISBN 90-2473633-1.

Rohlf, F.J., (1993). NTSYS-pc v. 1.8. Numerical taxonomy and multivariate analysis system, Setauket, NY: Applied Biostatistics Inc.

Rombach, M.C., Aguda, R.M., Shepard, B.M. \& Roberts, D.W. 1986 Infection of rice brown planthopper, Nilaparvata lugens (Homoptera: Delphacidae), by field application of entomopathogenic hyphomycetes (Deuteromycotina). Environmental Entomology 15 1070-1073.
Samson R.A. 1974 Paecilomyces and some allied hyphomycetes. In Studies in Mycology 6 Baarn: Centraalbureau voor Schimmelcultures.

Shimizu, S., Nishida, Y., Yoshioka, H. \& Matsumoto, T. 1991 Separation of chromosomal DNA molecules from Paecilomyces fumosoroseus by pulsed field electrophoresis. Journal of Invertibrate Pathology 58, 461-463.

Sneath, P.A. \& Sokal, R.R., (1973). Numerical Taxonomy, San Francisco: Freeman ISBN 0716706970.

Tigano-Milani, M.S., Honeycutt, R.J., Lacey, L., Assis, R., McClelland, M. \& Sobral, B.W.S. 1995a Genetic variability of Paecilomyces fumosoroseus isolates revealed by molecular markers. Journal of Invertebrate Pathology 65, 274-282.

Tigano-Milani, M.S., Samson, R.A., Martins, I. \& Sobral, B.W.S. 1995b DNA markers for differentiating isolates of Paecilomyces lilacinus. Microbiology 141, 239-245.

Valadares-Inglis, M.C. \& Peberdy, J.F. 1998 Variation in the electrophoretic karyotype of Brazilian strains of Metarhizium anisopliae. Genetics and Molecular Biology 21, 1415-4757.

Viaud, M., Couteaudier, Y., Levis, C. \& Riba, G. 1996 Genome organization in Beauveria bassiana: electrophoretic karyotype, gene mapping and telomeric fingerprint. Fungal Genetics and Biology 20, 175-183.

Williams, J.G., Kubelik, A.R., Livak, K.J., Rafalski, J.A. \& Tingey, S.V. 1990 DNA polymorphisms amplified by arbitrary primers are useful as genetic markers. Nucleic Acids Research 18, 6531-6535. 